\title{
Occupational asthma due to an emulsified oil mist
}

\author{
M S HENDY,' B E BEATTIE, ${ }^{2}$ AND P S BURGE' \\ From the Department of Thoracic Medicine, ' East Birmingham Hospital, Bordesley Green East, Birmingham \\ 9, and Lucas Electrical Limited, ${ }^{2}$ Hall Green, Birmingham, UK
}

ABSTRACT A toolsetter developed occupational asthma due to the oil mist generated by his lathe on which it was used as a coolant. The diagnosis was confirmed by serial measurements of peak expiratory flow at home and work, including a prolonged period away from work. Occupational type bronchial provocation tests were performed using the whole emulsified oil and its components separately. He reacted specifically to the whole emulsified oil and to the reodorant, a pine oil preparation. He also reacted to colophony, a constituent of the emulsifier.

Exposure to cutting oil mists is common in industrial nations.' Although bronchitis has been associated with the use of such agents, ${ }^{23}$ the occurrence of asthma has not previously been recorded. Cutting oils may be categorised into three major classes: straight mineral oils containing mineral oil but no water; emulsified oils containing mineral oil and water; and synthetic cutting fluids that do not contain mineral oil. The emusified oils, in addition, contain several additives including corrosion inhibitors, extreme pressure additives, antifoamers, colourants, germicides, and reodorants. The emulsified oils also become contaminated with bacteria during use.

We report a patient who presented with symptoms suggestive of occupational asthma in a factory where it had been previously unrecognised. The case illustrates the stages in uncovering a new cause of occupational asthma. A history suggestive of occupational asthma was confirmed by serial measurements of peak flow at home and work. This relation between a fall in peak flow and work exposure, however, only became clear after a prolonged period away from work. The precise causes of the occupational asthma were found by occupational type bronchial provocation testing to materials met at work. The patient reacted to pine oil, used as a reodorant, and to colophony, a constituent of the emulsifier, both present in the emulsified oil used at his workplace and both derived from pine trees.

\section{Case report}

A 63 year old man had been a toolsetter and machine operator for 43 years. He set up and oper-

Received 10 January 1983

Accepted 19 December 1983 ated capstans to cut metals to precise specification for the aircraft industry. He was exposed to the dusts of cobalt and tungsten when dry grinding his cutting tools; there was no exposure to zinc or chromium. The cutting piece was lubricated and cooled using the cutting oil "Superedge 4 blue" (BurmahCastrol). He presented with a ten year history of unproductive cough, wheeze, and progressive dyspnoea which symptomatically improved at weekends (away from work) and on holidays. He was a nonsmoker. There was no family history of allergic disease. He had diffuse expiratory wheezes, there were changes in his big toes compatible with chronic gout, and he was hypertensive (blood pressure 180/110 $\mathrm{mm} \mathrm{Hg}$ sitting). Skin prick tests to ten common inhaled allergens showed appreciable reactions only to house dust, house dust mite, and feathers. There was no blood or sputum eosinophilia. His chest radiograph showed clear lung fields, and the heart size was within normal limits. Lung function away from work showed (with \% predicted values in brackets) FEV 1.951 (60\%), FVC 4.551 (105\%), total lung capacity $8 \cdot 01(110 \%)$, residual volume $4 \cdot 1$ $\mathrm{l}(165 \%), \mathrm{T}_{\mathrm{L}} \mathrm{CO} 5.6(60 \%)$, and $\mathrm{KCO} 0.9(65 \%)$.

\section{SERIAL MEASUREMENTS OF PEAK FLOW}

The patient measured his own peak expiratory flow rate every two hours from waking to sleeping, using a mini-Wright peak flow meter. The records were made and analysed in a standard manner and the results are shown in fig 1 . During the first three weeks at work there was equivalent daily deterioration in mean peak flow; however, the changes were small with values about $30 \mathrm{l} / \mathrm{min}$ less on days at work, making the significance of these changes unclear. He then had 11 weeks of work with acute gout in his elbow. During this time his mean peak 
Results of provocation tests

\begin{tabular}{|c|c|c|c|c|c|}
\hline & Material tested & Exposure method & Exposure time (mins) & $\%$ Fall in FEV & Baseline FEV \\
\hline \multirow{2}{*}{ Hard metals } & Cobalt & Tipping dust & 30 & 3 & $2 \cdot 05$ \\
\hline & Tungsten & Tipping dust & 30 & 10 & $2 \cdot 00$ \\
\hline \multirow[t]{5}{*}{ Emulsified oils } & Clean & Stirring & 30 & 23 & 1.95 \\
\hline & Used & Stirring & 30 & 25 & $2 \cdot 05$ \\
\hline & Biocide & Stirring & 30 & 0 & 1.95 \\
\hline & Mineral oil & Stirring & 30 & 12 & $2 \cdot 20$ \\
\hline & Emulsifier & Stirring & 30 & 8 & $2 \cdot 20$ \\
\hline \multirow{3}{*}{$\begin{array}{l}\text { Emulsified oil } \\
\text { constituents }\end{array}$} & Colourant & Stirring & 30 & 8 & 1.90 \\
\hline & Reodorant & Stirring & 30 & 40 & $2 \cdot 25$ \\
\hline & Aliphatic hydrocarbon & Stirring & 30 & 0 & 2.30 \\
\hline Colophony & American WW & Heating at $250^{\circ} \mathrm{C}$ & 5 & 44 & 2.40 \\
\hline Turpentine & & Stirring & 20 & 37 & $2 \cdot 40$ \\
\hline
\end{tabular}

flow improved from around 200 to $340 \mathrm{l} / \mathrm{min}$. On returning to work the deterioration was much clearer with a fall of $100 \mathrm{l} / \mathrm{min}$ in daily mean peak flow showing a progressive daily deterioration pattern.

\section{BRONCHIAL PROVOCATION TESTING}

Simulated occupational type provocation tests were made with the patient in hospital. He was off work, and a minimum of one week was allowed to elapse between exposures to new agents. $\mathrm{FEV}_{1}$ recordings were made using a dry wedge spirometer (Vitalograph); the higher of the two best readings within 0.051 of each other was chosen on each occasion. A steady baseline was obtained for a 12 hour period starting at 8.30 am with the patient receiving salbutamol $2 \mathrm{mg}$ by mouth, a salbutamol inhaler 200 $\mu \mathrm{g}$, and an ipratropium inhaler $40 \mu \mathrm{g}$ every two hours on each of the exposure days. Provocation testing was performed when the patient had a stable $\mathrm{FEV}_{1}$ of around 2.1 1 . Exposure started at $8.30 \mathrm{am}$ on each occasion and the table shows the results of the bronchial provocation tests. He was exposed in turn by tipping from one tray to another to fine dusts of tungsten and cobalt up to a maximum of $\mathbf{3 0}$ minutes in each case. The patient was asked to breathe normally during the tipping process. There was no significant fall in $\mathrm{FEV}_{1}$ after exposure to either of these metals. He was then exposed to the emulsified oil with which he worked by stirring the oil and breathing normally but close to the beaker. Exposure for five minutes did not produce an appreciable reaction. Exposure for 30 minutes, however, produced a systemic reaction characterised by headache, muscular aches, and chest tightness. Figure 2 shows his $\mathrm{FEV}_{1}$ recordings. One hour after exposure the FEV had fallen $23 \%$ from the baseline of 1.951 . Subsequent exposure to the constituents of the cuttng oid showed a considerable reaction to the reodorant (fig 3 ) but not to any of the other components. Exposure to colophony heated at $250^{\circ} \mathrm{C}$ for five minutes pro duced an immediate bronchial reaction with no reaction in a simultaneously exposed asthmatic. The control asthmatic reacted to histamine after a two minute exposure at $8 \mathrm{mg} / \mathrm{ml}$ and gave informed consent for both studies.

Exposure to artists' turpentine at room temperature produced a similar reaction to that induced by the reodorant (fig 4) which was blocked by cromoglycate pretreatment.

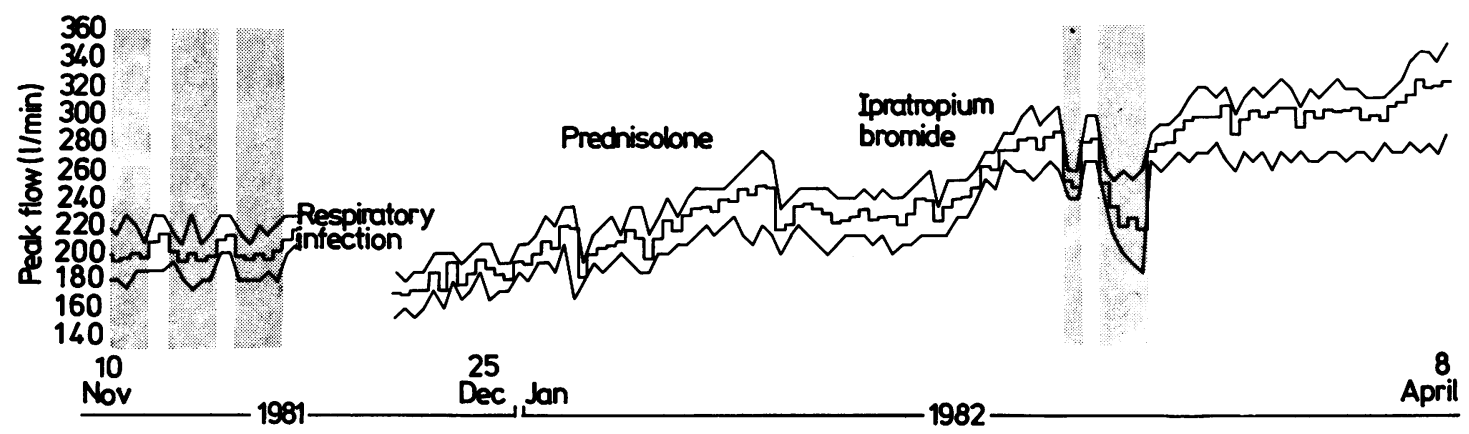

Fig 1 Mean, maximum, and minimum peak flow at home and work. Days at work have a shaded background. During first three weeks there is only minor improvement away from work. A more prolonged period off work resulted in considerable improvement with pronounced deterioration on return to work. 


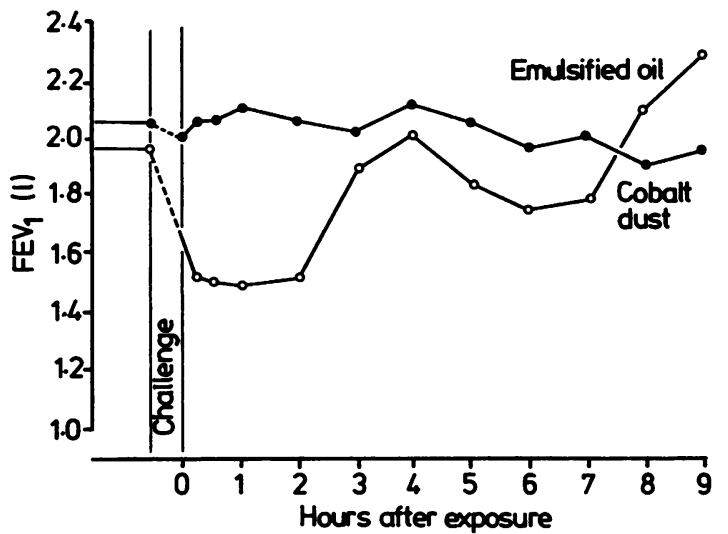

Fig 2 Bronchial provocation testing showing an immediate asthmatic reaction after a 30 minute exposure to clean emulsified oil with no reaction after exposure to cobalt dust.

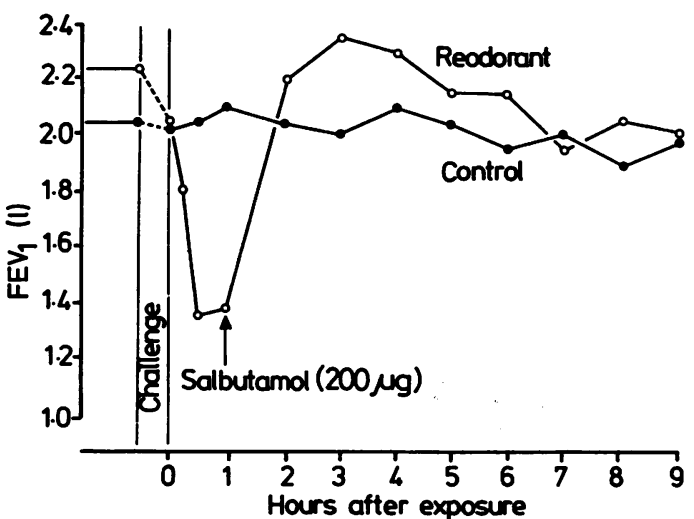

Fig 3 Bronchial provocation testing showing an immediate asthmatic reaction to pine oil reodorant.

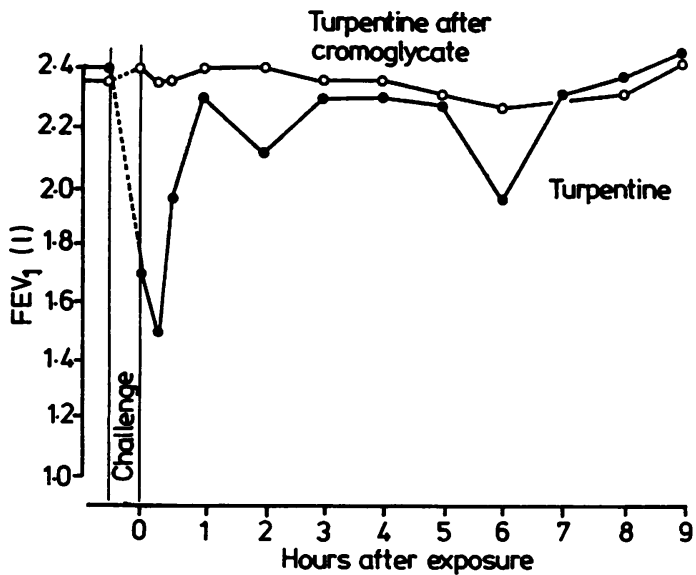

Fig 4 Bronchial provocation testing with artists' turpentine showing an immediate reaction to turpentine that was blocked by cromoglycate pretreatment.

\section{Discussion}

This patient presented with features suggestive of chronic airflow obstruction; he had a chronic cough and progressive dyspnoea and airways obstruction that was unresponsive to inhaled salbutamol. Serial measurements of peak flow at work initially failed to show any acute reactions to work; there were, however, slightly lower mean daily peak flow readings on workdays compared with restdays (fig 1). This is often seen in workers with the more severe forms of occupational asthma. ${ }^{4}$ Substantial recovery was seen during an 11 week period off work but subsequent return to work clearly documented occupational asthma with considerable falls in peak flow related to work exposure. Serial measurements of peak flow showed deterioration in $5 / 5$ periods at work and improvement in $5 / 5$ periods off work. Previous work has shown that provided improvement away from work or deterioration at work is seen in at least $75 \%$ of possible weeks, such records have a $100 \%$ specificity for the detection of occupational asthma but are relatively insensitive $(45 \%-70 \%) .{ }^{56}$ Serial measurements of peak flow are unable to identify the specific cause of a worker's symptom for which bronchial provocation testing is required.

Occupational type bronchial provocation testing first requires satisfactory control data, in particular stable values for $\mathrm{FEV}_{1}$ for $10-12$ hours. In this case regular beclomethasone, salbutamol, and ipratropium were needed to achieve baseline stability. Such treatment may block asthmatic reactions, but in practice larger exposures can usually overcome any protective effect of these drugs. The initial bronchial provocation tests were with components of hard metal, the only recognised cause of occupational asthma in grinders, drillers, and cutters. Tungsten carbide (which is thought to be inert) was used as the control for cobalt, which is responsible for occupational asthma in hard metal workers. There was no reaction to either exposure.

Emulsified oils, as used by our patient at work, are contaminated by the metals that they are cooling and by bacteria. The workers inhale the emulsified oil after it has been nebulised by hitting the rotating workpiece which becomes heated by friction. Our patient reacted to unused emulsified oil at room temperature, thereby eliminating bacteria, endotoxin, and dissolved metals as the cause of his asthma. Challenge testing by stirring clean oil was only likely to produce appreciable exposures to volatile components of the emulsified oil. The only constituent causing a reaction by this method was the reodorant, which was pine oil. $\mathrm{He}$ also reacted to artists' grade turpentine at room temperature and colophony heated at $250^{\circ} \mathrm{C}$. 
Pine oil is produced by steam distillation of stumps and old roots of pine trees in which turpenes have become oxidised and hydrolysed. It seems to be similar to turpentine. Pine resin, produced by tapping pine trees, has two important constituents when distilled, the distillate is turpentine and the residue colophony. Pine oil is, therefore, closely related to turpentine, but is likely to be less pure. Colophony is a mixture of resin acids and a neutral fraction. The emulsifier used in the emulsified oil contains $17 \%$ tall oil, which is a source of colophony produced as a byproduct of the Kraft process of paper manufacture from wood chips. Our patient reacted to both artists' grade turpentine at room temperature and to colophony (produced from pine resin) heated at $250^{\circ} \mathrm{C}$. It is not clear whether this represents a sensitivity to a single constituent of both materials or two separate substances. The resin acids of colophony can be detected around pine trees $\mathrm{C}$ Edmonds, personal communication) and may also be detected when colophony is heated at $150^{\circ} \mathrm{C}$. Above about $180^{\circ} \mathrm{C}$ some of the resin acids are broken down to form aldehydes, ${ }^{8}$ but resin acids are still a major constituent of the fume when colophony is heated at $350^{\circ} \mathrm{C}$, as in electronics soldering. Colophony is an irritant at high concentrations, particularly to the eyes, and the threshold limit value for colophony fumes is based on its irritant properties. Colophony fumes are a well recognised cause of occupational asthma ${ }^{910}$; studies comparing the threshold levels of colophony fume and of inhaled histamine have shown only a weak correlation between the two, suggesting that the reactions to colophony are specific and not usually due to nonspecific irritation." Colophony fumes have occasionally caused asthmatic reactions that are thought to be irritant, but the level of exposure required to produce irritant reactions, even in those with the greatest non-specific reactivity, were subjectively much higher than those produced in the present study. In addition there was no reaction in an asthmatic subject simultaneously exposed with our patient. It is, therefore, unlikely that the reaction to colophony was produced by non-specific irritation.
The mechanism of the reaction to turpentine (and pine oil) is much less clear. There are no reports of groups with increased non-specific bronchial reactivity who have been exposed to turpentine fumes. The only previously published data relate to two electronic workers with occupational asthma due to colophony who failed to react to a 30 minute exposure to turpentine painted on to a flat surface. ${ }^{9}$

It is not possible from the current data to differentiate between the irritant or an allergic mechanism for the reaction to turpentine.

We thank Peter Oates and Richard Rycroft for constructive criticism and technical help.

\section{References}

' Oxhøj H, Andreasen H, Henius UM. Respiratory symptoms and ventilatory lung function in machine shop workers exposed to coolant lubricants. Eur J Respir Dis 1982;63:85-9.

${ }^{2}$ Järvolm B. Mineral oils - studies on health and effects in the engineering industry. Gothenburg: University of Gothenburg, 1981. (Thesis.)

${ }^{3}$ Järvolm B. Cutting oil mist and bronchitis. Eur J Respir Dis 1982; 63:79-83.

${ }^{4}$ Burge PS. Could you be overlooking occupational asthma? Journal of Respiratory Disease 1982;3:97-112.

5 Burge PS, O'Brien IM, Harries MG. Peak flow rate records iळ the diagnosis of occupational asthma due to colophon Thorax 1979;34:308-16.

- Burge PS, O'Brien IM, Harries MG. Peak flow rate records is the diagnosis of occupational asthma due to isocyanates. Thorax 1979;34:317-23.

' Burge PS, Edge G, Hawkins R, White V, Newman Taylor AJ. Occupational asthma in a factory making flux-cored solder containing colophony. Thorax 1981;36:828-34.

- Drugov YS, Murav'eva GV. Gaschromotographic analysis of air contaminated by resin degradation products. Zhurnel Analiticheskoi Khimii 1976;31:2205-11.

' Burge PS, Harries MG, O'Brien IM, Pepys J. Bronchial provocation studies in workers exposed to the fumes of electronic soldering fluxes. Clin Allergy 1980;10:137-49.

${ }^{10}$ Fawcett IW, Newman Taylor AJ, Pepys J. Asthma due to inhaled chemical agents - fumes from "Multicore" soldering flux and colophony resin. Clinical Allergy 1976;6:577-85.

"Burge PS. Non-specific bronchial hyperreactivity in workers exposed to toluene di-isocyanate, diphenylmethane diisocyanate and colophony. Journal of Respiratory Disease 1982;63, suppl 123:65-77. 